\title{
A conversation with Helen Hobbs
}

$\mathbf{H}$ elen Hobbs, an HHMI investigator, professor at the University of Texas Southwestern Medical Center, and director of the Dallas Heart Study, is best known for her research focused on identifying genetic factors that predispose people to developing metabolic disorders and heart disease. By studying outliers in the Dallas Heart Study, Hobbs (Figure 1) uncovered a genetic defect responsible for low blood LDL cholesterol levels. This work on the target PCSK9 has led to a hotbed of drug development, with FDA approval likely this year. To hear Hobbs's stories about being mortified by initially getting some Cs in high school, her love of the wide, open spaces in Texas, and how she considered a stint as a cruise ship doctor, find the full interview on the JCI website (https://www.jci.org/videos/cgms).

JCI: What were your parents like?

Hobbs: My parents married when they were 19 and 21 when my father came back from World War II. He did his first year and a half at Harvard before going off to war, but never graduated. He got married, moved to Puerto Rico to run a slip factory, and then wrote every month to Harvard Business School to try to get in. Finally, they let him in, even though he didn't have an undergraduate degree. He went to business school, and that's when I was born, in Boston. My mother was a very tough, but loving woman. She was very exacting.

JCI: Did your father's work as a businessman leave an early impression?

Hobbs: I never wanted to do business, even though my father loved his work, and all three of my brothers went into business. My father wanted to have each one of us represent one of the professions: one of my brothers was to be the businessman, one brother to be a lawyer, one brother to be a teacher, and I was to... Even though he always told me I had to have a career, he didn't have a set one for me. But he was the person who got me thinking about medicine. When I was about seven, we were watching a program on TV about how $70 \%$ of the doctors in Russia were women. He turned to me, and he said, "You know, I think you would make a great doctor."

I was interested in art and art history. Not a good artist myself, but loved art. By the middle of my freshman year at the University of Pennsylvania, I looked at all the course offerings and I just couldn't see ahead four years. Plus I had this wanderlust. I had grown up outside of Boston, and all of my brothers went to Harvard, and I really wanted to go west. So I applied to Stanford and got in and went there sight unseen. Once there, I joined the human

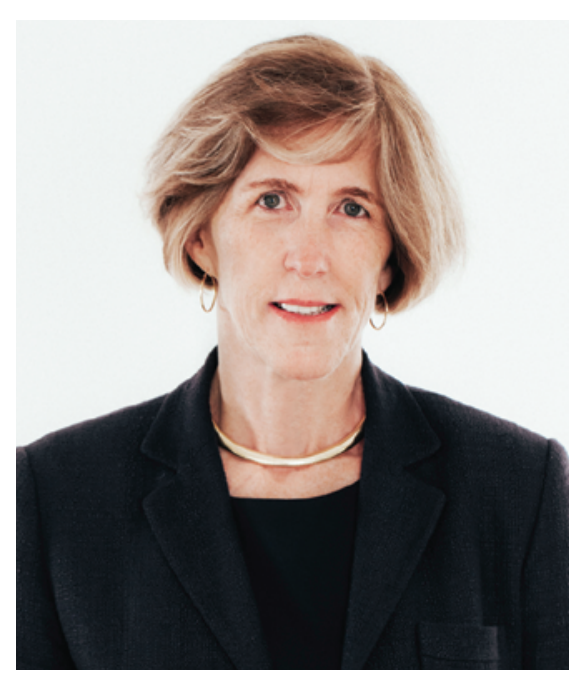

Figure 1. Helen Hobbs on July 23, 2015. Image credit: Alexey Levchenko.

biology program, but I also took everything else - I took intro to everything.

I was thinking that I was going to be a Doctor Without Borders. Igot very interested in Africa because I had worked in high school on Grand Cayman Island with a group called Crossroads Africa. I met a number of people who had spent time in Africa, and they made it sound very interesting. I lived in a Ghanaian home in Accra, and I worked in a maternal/child clinic and a preschool. I went with visiting nurses to see all the patients that had leprosy or other infectious diseases. It didn't take me long to realize I did not want to be a Doctor Without Borders. I did, however, do all my applications to medical school when I was there. I came back after six months and did my interviews and ended up going to medical school at Case Western Reserve.

JCI: How did you pick Columbia for your internship?

Hobbs: Charles Carpenter was head of medicine at Case Western. He said to me, "There are two places that you should go: the Brigham in Boston or Parkland Hospital in Dallas." I didn't want to go to Texas, but I didn't want to go back to Boston either. I looked at all the programs in New York City and thought that Columbia was best suited to what I wanted.

While there, I met my husband; he was my resident in the emergency room. He had gone to Southwestern Medical School and received the protocols from their weekly grand rounds. The emphasis was on understanding the science of medicine. Unsaid was that if you understand pathophysiology, then you could arrive at a diagnosis.

My husband wanted to go back to Dallas. The minute I walked into Parkland, I loved it. I met Donald Seldin and I had never met anybody like him before. So intelligent, so incisive, so wise. Even on a short visit, I was completely captivated.

JCI: After you moved there, Seldin made you chief resident in recognition of your clinical skills. But he then guided you to scientific bench training.

Hobbs: I would characterize myself up to this point as a dilettante. I knew that I liked clinical endocrinology. But Seldin just shook his head and said, "No, that's not for you, it will never sustain you. After five years you'll be looking for something else to do. I really think you should go into a laboratory."

I realized that the people that I enjoyed the most as physicians were the people who were the scientists. I felt an affinity for the way that they thought, the way that they handle problems, the kinds of things that they thought interesting. Then he said, "And I think you should go into the Brown and Goldstein laboratory." My first thought was, "Lipoproteins. Oh, no. So boring." That just tells you how little I understood about science.

JCI: At some point, you got hooked.

Hobbs: They had just cloned the LDL receptor cDNA. Tom Südhof was there, and 
he was characterizing the gene. I was looking at what they had collected - 129 skin biopsy specimens from patients who had homozygous familial hypercholesterolemia. My first project was to characterize the mutations that resulted in the production of no protein. As I was doing Southern blotting looking for structural rearrangements in the LDL receptor gene, I was focusing on a group of five patients that didn't make any messenger RNA. I had written everybody by name on the gel, and all the names were French - from Quebec province. Then I found out that they all had a deletion in their gene that included the promoter in exon one. I went up to Montreal to get blood samples from a large number of patients with familial hypercholesterolemia, and we discovered that $60 \%$ of the alleles in that population were due to this deletion, which was due to the founder effect. The results on one blot told a much more expansive story.

JCI: This led you down the path of population genetics. How did you get started on the Dallas Heart Study?

Hobbs: Every time I'd wanted to figure out whether any of these genes that we had identified played a role in hypercholesterolemia in the general population, I had to go to established studies. I had to write a proposal, which would usually die a painful death. I never was successful at getting any samples from the established population-based studies. We decided to apply for a large grant from the Donald W. Reynolds Foundation.

Together with Ron Victor, I drafted a proposal to establish a "human biology laboratory" that was representative of the genetic diversity in Dallas County: half the population in the study is African-American, $15 \%$ Hispanic. We wanted to have the phenotypes be as precise as possible to minimize phenotypic noise. We also wanted to be able to go back to each participant, so we specified this in the consent form.

It was at this time that I joined forces with Jonathan Cohen, because we have a very complimentary skill set. Once we got the grant, we started sequencing DNA right away, starting at the extreme ends of trait distributions. At this time (year 2000) the general view was that common diseases were due to common variants - that a collection of common variants caused common diseases. Instead, we wondered whether rare variants could cumulatively contribute to common diseases. Rare vari- ants with large phenotypic effects would get us to function more rapidly.

JCI: How quickly did you identify the patients with genetic defects in PCSK9?

Hobbs: We actually started with HDL. Not something that we worked on, but the genetics were easier - only three genes were known to cause low levels of HDL cholesterol. So we sequenced these genes in the individuals in the population that had the lowest and the highest HDL levels, and we compared the number of coding mutations, nonsynonymous mutations, and nonsense mutations in the two extremes. We threw out all the ones that were in both extremes, and then we simply counted and compared the frequencies in the extremes of the distribution.

It turned out there was a huge excess of low-frequency alleles, most of them represented only once in the entire group, that were in the low HDL group compared to the high HDL group. We replicated our findings in another population from Canada in collaboration with Ruth McPherson, and we also did functional studies that showed that there was an efflux defect with these particular mutations, most of them in $A B C A 1$. Incidentally, that paper got turned down by JCI, but accepted by Science. It didn't even go out for review.

JCI: We make some mistakes!

Hobbs: That study told us that rare variants cumulatively contribute to complex traits. As this was all happening, there was a great paper in Nature Genetics from Catherine Boileau's group where they had identified a new gene, PCSK9, with selected missense mutations that caused a disease that looked just like familial hypoglycemia.

Jay Horton told me about how he overexpressed PCSK9 in the liver - both the mutant forms of PCSK9 as well as the wildtype form of PCSK9. In all cases, the LDL receptor disappeared without a change in messenger RNA and the plasma levels of LDL went really high. This was a really interesting result, particularly as overexpressing the wild-type protein had this effect. This strongly suggested these mutations were gain-of-function mutations. We thought the likelihood that we would find a gain-of-function mutation in the Dallas Heart Study was very low, given the size of the population. So we looked for loss-of-function mutations and predicted that the phenotype would be just the opposite: very low LDL choles- terol levels. We went to our population and sequenced the coding regions of PCSK9 in the individuals with the lowest LDL levels and hit pay dirt right away when we found a nonsense mutation. We found our first and then a second nonsense mutation in the African-Americans. We took those two mutations, assayed the whole group of African-Americans, and one out of every 50 had a nonsense mutation. When we looked, the LDL levels were reduced by about $40 \%$ in the 33 people we identified with a nonsense mutation compared to the ones who didn't have the nonsense mutation.

JCI: When were you able to figure out that a mutation in PCSK9 led to a consequent reduction in heart disease?

Hobbs: We went to a collaborator (Eric Boerwinkle) who runs the genetic part of the ARIC [Atherosclerosis Risk in Communities] study, a biracial prospective study. The cohort had been followed at that time for 15 years, and we assayed for the PCSK9 variant and looked at who developed heart disease over a 15 -year period. The results were better than we ever expected. We saw dramatic reductions in heart disease in the African-American population: a $28 \%$ reduction in LDL leading to an $88 \%$ reduction in coronary events. We also found a sequence variation in Caucasians. It had a mild effect on PCSK9 function, with a 15\% reduction in LDL, but still a $46 \%$ reduction in coronary disease.

JCI: You've been quoted as saying, "Geneticists took a little while to understand this, but the pharmaceutical companies got it right away."

Hobbs: Absolutely. I would talk at genetics meetings, and there just was very little interest initially. But there were a number of companies that picked it up. The rest is history. There's an antibody in ongoing trials and an advisory board has recommended that the FDA approve it sometime this summer [2015].

JCI: Exciting. What else do you think you might have done if you weren't a scientist?

Hobbs: I often think about what would have happened if I had stayed at Columbia, if I had never met Donald Seldin. When I was young, I played the piano. I wanted to be a pianist. That was totally unrealistic. I think I could've been successful in other endeavors, but I am glad that I've taken this path.

\section{Ushma S. Neill}

